\title{
Evaluating larval mosquito resource partitioning in western Kenya using stable isotopes of carbon and nitrogen
}

Thomas M Gilbreath III', Eliningaya J Kweka², Yaw A Afrane ${ }^{3}$, Andrew K Githeko ${ }^{3}$ and Guiyun Yan ${ }^{4 *}$

\begin{abstract}
Background: In sub-Saharan Africa, malaria, transmitted by the Anopheles mosquito, remains one of the foremost public health concerns. Anopheles gambiae, the primary malaria vector in sub-Saharan Africa, is typically associated with ephemeral, sunlit habitats; however, An. gambiae larvae often share these habitats with other anophelines along with other disease-transmitting and benign mosquito species. Resource limitations within habitats can constrain larval density and development, and this drives competitive interactions among and between species.
\end{abstract}

Methods: We used naturally occurring stable isotope ratios of carbon and nitrogen to identify resource partitioning among co-occurring larval species in microcosms and natural habitats in western Kenya. We used two and three source mixing models to estimate resource utilization (i.e. bacteria, algae, organic matter) by larvae.

Results: Laboratory experiments revealed larval $\delta^{13} \mathrm{C}$ and $\delta^{15} \mathrm{~N}$ composition to reflect the food sources they were reared on. Resource partitioning was demonstrated between An. gambiae and Culex quinquefasciatus larvae sharing the same microcosms. Differences in larval $\delta^{13} \mathrm{C}$ and $\delta^{15} \mathrm{~N}$ content was also evident in natural habitats, and Anopheles species were consistently more enriched in $\delta^{13} \mathrm{C}$ when compared to culicine larvae.

Conclusions: These observations demonstrate inter-specific resource partitioning between $C X$. quinquefasciatus and An. gambiae larvae in natural habitats in western Kenya. This information may be translated into opportunities for targeted larval control efforts by limiting specific larval food resources, or through bio-control utilizing competitors at the same trophic level.

Keywords: An. gambiae, Stable isotopes, Resource partitioning, $\delta^{13} \mathrm{C}, \delta^{15} \mathrm{~N}$, Trophic preferences

\section{Background}

Larval density and inter-/intra-specific competition have a significant effect on the development and growth rates of mosquito larvae in their aquatic habitats [1-3]. Higher larval densities and competition between An. gambiae s.s. and $A n$. arabiensis result in extended development times, and several studies indicate that this may be a direct result of increased competition for microbial food resources [3-5]. This is particularly noteworthy for An. gambiae s.l. larvae, because they typically inhabit temporary, sunlit pools and increased development times may exceed the duration of aquatic habitats [6-8]. Although larval competition

\footnotetext{
* Correspondence: guiyuny@uci.edu

${ }^{4}$ Program in Public Health, University of California, Irvine, CA 92697, USA

Full list of author information is available at the end of the article
}

for food resources likely plays an important role in mosquito habitat productivity, relatively few studies have examined the actual partitioning of resources between and among species [9].

Extensive work has been carried out in characterizing larval habitats of malaria vectors. An. gambiae larvae have been found in a suite of habitat types including abandoned goldmines, brick making pits, ponds, agricultural drainage ditches and puddles [10,11]. When habitat size falls below $\sim 1 \mathrm{~m}^{3}$, habitat stability and pupal occurrence decreases rapidly [11]; however, predation of larvae is typically lower and water temperatures are often higher in smaller habitats [12,13]. Minakawa found a significant correlation between habitat availability and the density of indoor resting mosquitoes in homes [6]. 
Stable isotopes represent a valuable yet not fully realized technology for mosquito ecology. Stable isotopes are convenient, naturally occurring tracers that are safe and non-radioactive. There are few examples of stable isotopes being used in vector biology studies; however, Hood-Nowotny and Knols illustrated a wide range of potential applications of stable isotopes in entomological studies and the falling costs and rapidly improving technology of stable isotope analysis [14]. Hood-Nowotny and others demonstrated the use of ${ }^{13} \mathrm{C}$ enrichment as a population marker in a sterile insect technique context [15]. Recently, stable isotopes were used to identify the detrital resource base of Aedes triseriatus in tree holes [16]. Although natural abundance stable isotope studies have been used for several decades to clarify trophic relationships in aquatic ecosystems [17-19], few have specifically looked at resource partitioning among co-occurring species of mosquito larvae. Stable isotope ratios of carbon and nitrogen in invertebrate larvae reflect the larval diet [20], thus differences in larval diet should be reflected in larval isotope signatures. Winters and Yee were able to demonstrate a higher proportion of $\delta^{15} \mathrm{~N}$ in Aedes albopictus relative to Culex restuans, which was indicative of a stronger association of Ae. albopictus larvae with detritus as a food resource [9].

Stable isotopes may also provide a means to examine the relationship between larvae and their potential predators. We have previously determined dragon fly nymphs to be one of the most efficient larval predators in the region and in microcosm studies, An. gambiae DNA was detected in dragonfly nymph guts [21].

In this study, we sought to use naturally occurring stable isotopes to examine inter- and intra-specific resource partitioning among larval mosquitoes. We examined inter- and intra-specific resource partitioning by measuring the carbon and nitrogen stable isotope ratios of larvae sharing the same habitats in western Kenya. We hypothesized that stable isotope ratios of carbon and nitrogen would be able to identify resource partitioning among larval species, and that Anopheles sp. would have isotopic signatures indicative of strong competition for resources, while differences in culicine and anopheline feeding strategies would demonstrate significant resource partitioning among the two genera. Dragon fly nymphs were also collected to identify stable isotopic signatures indicative of food choice. We also conducted a laboratory control study to assess trophic shift, or the difference in $\delta^{13} \mathrm{C}$ and $\delta^{15} \mathrm{~N}$ composition of larvae compared to their food resources caused by larval metabolism [22]. Finally, to compliment our laboratory and field experiments, we conducted microcosm experiments to demonstrate resource partitioning between genera in relatively simple environments, lacking the complexity of natural habitats.

\section{Methods}

\section{Laboratory experiments}

Anopheles gambiae G3 strain mosquitoes, obtained from Malaria Research and Reference Reagent Resource Center (http://www.mr4.org), were used in the laboratory experiments. Culex quinquefaciatus larvae reared on Tetramin fish food (Spectrum Brands, Inc., Madison, WI, USA) were obtained from the Anthony James laboratory at UCI. Mosquitoes were reared in a walk-in insectary regulated at a relative humidity of $75 \%$, temperature of $26^{\circ} \mathrm{C}$, and 12:12 hour light-dark cycle. Mosquito larvae were reared in trays of 100 first-instar larvae per liter of water. $C x$. quinquefaciatus and An. gambiae larvae were reared from first instar on fish food in order to determine the trophic shift associated with larval metabolism. This also served to identify differences in isotopic discrimination between the two species. An. gambiae larvae were reared on two different food types, fish food or brewer's yeast, to test the utility of stable isotopes in determining what food resources were consumed. Third instar larvae were collected into paper cups and approximately 30 minutes were allowed for gut clearance before larvae were rinsed three times with distilled water. Larvae ( $1 \mathrm{mg} / \mathrm{sample})$ and food samples $(2.6 \mathrm{mg} / \mathrm{sample})$ were oven dried overnight at $50^{\circ} \mathrm{C}$ prior to sample weighing and processing. Three samples were analyzed for each sample type, and for larval samples up to four larvae were pooled to obtain adequate sample weight for analysis.

\section{Microcosm experiments}

To examine resource partitioning in a more controlled setting relative to natural habitats, we established an array of microcosms at the Kenya Medical Research Institute (KEMRI) in Kisian, Kenya. The microcosms were constructed using $60 \mathrm{~cm}$ diameter washtubs and approximately four liters of local top-soil were added to each. Soil was well mixed prior to addition to keep soil as similar as possible across microcosms. Rainwater was collected from roof runoff in Kisian, Kenya and approximately six liters were added to each microcosm. Microcosms were placed in full sun, screened with a light mesh to prevent oviposition by wild mosquitoes and left for five days to allow for microbial colonization prior to addition of larvae as done previously [23]. Colonies of Cx. quinquefasciatus and Kisian strain An. gambiae s.s. were used for microcosm experiments. The colonies were maintained at the insectary in Kisian. One hundred first instar larvae of each species were added to each microcosm. Water levels were maintained as needed by the addition of rainwater. Third and fourth instar larvae were collected, held for 30 minutes for gut clearance and rinsed three times with distilled water. Detritus and filamentous algae samples were also collected. Filamentous algae were rinsed thoroughly with distilled water prior to desiccation. Samples were dried for 48 hours in a 
desiccator, and stored with desiccant for transport to the United States further processing. Three replicates were taken for analysis for each sample type, and for larval samples desiccated larvae were ground and up to four larvae were pooled per sample to obtain adequate weight for analysis.

\section{Natural habitat sample collection}

Sampling of natural habitats was conducted in Iguhu, Kenya (1,500 m above sea level) in the western Kenya highlands between October 2009 and August 2010. Four selected natural habitats consisted of abandoned goldmines and agricultural drainage ditches. Two habitat types were utilized in order to determine if the degree of resource partitioning was consistent between habitats. Habitats were chosen based on the co-occurrence of two or more mosquito species, at least one of which was $A n$. gambiae. Sample collections were made from each habitat on a single day. Third and fourth instar larvae were collected using a standard dipper and transferred to the lab on ice in water from their respective habitats. Larvae were allowed several hours for gut clearance. Detritus and filamentous algae samples were collected and prepared using the same methods as the microcosm experiments. In 2011, allochthonous C3 plant material cow dung and dragon fly nymphs were collected in addition to larvae. Dragonfly nymphs were held for several hours to allow for gut clearance, and cleaned with distilled water. Samples were prepared for processing following the same methods as those in the microcosm experiments.

\section{Stable isotope analysis}

Samples of insects ( $0.75 \mathrm{mg} / \mathrm{sample})$, detritus ( $15 \mathrm{mg} / \mathrm{sample})$, algae (1.5 mg/sample), and cow dung ( $1.5 \mathrm{mg} / \mathrm{sample})$ were analyzed for ${ }^{13} \mathrm{C}$ and ${ }^{15} \mathrm{~N}$ isotopes at the University of California, Davis Stable Isotope Facility. Detritus samples were fumed for 12 hours with concentrated $\mathrm{HCl}$ to remove inorganic carbon. Samples were analyzed using a PDZ Europa ANCA-GSL elemental analyzer interfaced to a PDZ Europa 20-20 isotope ratio mass spectrometer (Sercon Ltd., Cheshire, UK). Samples were combusted at $1000^{\circ} \mathrm{C}$ in a reactor packed with chromium oxide and silvered cobaltous/cobaltic oxide. Following combustion, oxides were removed in a reduction reactor (reduced copper at $650^{\circ} \mathrm{C}$ ). The helium carrier then flowed through a magnesium perchlorate water trap. $\mathrm{N}_{2}$ and $\mathrm{CO}_{2}$ were separated on a Carbosieve GC column $\left(65^{\circ} \mathrm{C}, 65 \mathrm{~mL} / \mathrm{min}\right)$ before entering the IRMS. During analysis, samples were interspersed with several replicates of at least two different laboratory standards. These laboratory standards, which were selected to be compositionally similar to the samples being analyzed, have been previously calibrated against NIST Standard Reference Materials (IAEA-N1, IAEA-N2, IAEA-N3, USGS-40, and
USGS-41). Each sample's preliminary isotope ratio was measured relative to the reference gases analyzed with each sample. These preliminary values were finalized by correcting the values for the entire batch based on the known values of the included laboratory standards, which results in corrected $\delta^{13} \mathrm{C}$ and $\delta^{15} \mathrm{~N}$ values. $\delta^{13} \mathrm{C}$ values are typically depleted in the heavier isotope (negative) while $\delta^{15} \mathrm{~N}$ values are enriched (positive) relative to international standards [14]. Samples from goldmine three and the microcosm experiments were obtained in 2011 and were analyzed using similar, previously published protocols at the University of California, Irvine Stable Isotope Facility [24].

\section{Data analyses}

Data analyses were carried out using JMP Statistical Discovery Software statistics program (SAS Institute, Cary, NC). For laboratory and microcosm experiments, differences in $\delta^{13} \mathrm{C}$ and $\delta^{15} \mathrm{~N}$ between $C x$. quinquefaciatus and An. gambiae were compared using the paired student's t-test. Welch's t-test was used to compare $\delta^{13} \mathrm{C}$ and $\delta^{15} \mathrm{~N}$ of mosquito species with samples that had unequal variance. Separate tests were used for ${ }^{13} \mathrm{C}$ and ${ }^{15} \mathrm{~N}$. We used analysis of variance (ANOVA) to compare $\delta^{13} \mathrm{C}$ and $\delta^{15} \mathrm{~N}$ signatures of the co-occurring mosquito species within each habitat for the natural habitat experiments. To examine the relative contribution of potential food sources to target species, we used two and three source mixing models made available by Phillips and Gregg (IsoError, version 1.04; http://www.epa.gov/wed/pages/models/stableIsotopes/isotopes.htm) [25]. Two and three source mixing models allow for estimation of the proportional contributions of food sources to the consumer, and they take into account the mean, standard deviations and sample number for both $\delta^{13} \mathrm{C}$ and $\delta^{15} \mathrm{~N}$ values.

\section{Results}

\section{Laboratory experiments}

We conducted experiments in the laboratory to determine whether carbon and nitrogen stable isotope ratios were able to indicate food resource differences and similarities between Cx. quinquefasciatus and An. gambiae larvae. Carbon and nitrogen isotopic signatures of $C x$. quinquefasciatus and $A n$. gambiae larvae reared from first instar on Tetramin fish food were not significantly different $\left(\delta^{13} \mathrm{C}, \mathrm{t}=0.66, \mathrm{df}=4, \mathrm{P}=\right.$ 0.54; $\delta^{15} \mathrm{~N}, \mathrm{t}=0.09, \mathrm{df}=4, \mathrm{P}=0.93$ ) (Figure 1). Both larval species were slightly enriched in ${ }^{13} \mathrm{C}$ when compared to the dietary source; however, the carbon enrichment was negligible relative to isotopic discrimination found in microcosm and natural habitat experiments. When An. gambiae first instar larvae from the same laboratory colony were reared on yeast or fish food alone, the carbon and nitrogen isotopic signatures reflected the food source (An. gambiae reared on fish food and yeast; Welch's t-test; $\delta^{13} \mathrm{C}, \mathrm{t}=104.20, \mathrm{df}=3.0$, $\left.\mathrm{P}<0.0001 ; \delta^{15} \mathrm{~N}, \mathrm{t}=19.97, \mathrm{df}=2.2, \mathrm{P}=0.0015\right)$ (Figure 1 ). 


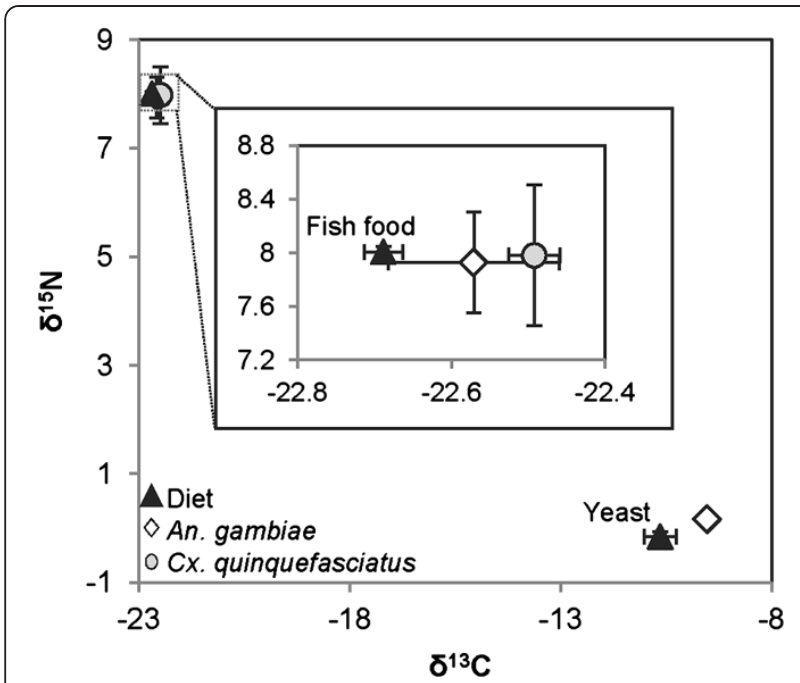

Figure $1 \delta^{13} \mathrm{C}$ and $\delta^{15} \mathrm{~N}$ composition of laboratory reared Anopheles gambiae and Culex quinquefasciatus on fish food and An. gambiae reared entirely on yeast. The inset panel expands the cluster showing isotopic ratios of An. gambiae, CX. quinquefasciatus and their laboratory diet (fish food).

\section{Microcosm experiments}

In microcosms with equal proportions of $C x$. quinquefasciatus and An. gambiae we demonstrated significant differences in both $\delta^{13} \mathrm{C}(\mathrm{t}=2.57, \mathrm{df}=5, P=0.0499)$ and $\delta^{15} \mathrm{~N}(\mathrm{t}=3.33, \mathrm{df}=5, P=0.0209)$ larval body tissue (Figure 2 ). A two source mixing model suggested that detrital and algal food resources contributed to mosquito tissue of both species. Elemental analysis of An. gambiae body content showed that $85.3 \%$ of and $38.1 \%$ of body nitrogen was attributed to algal resources, compared to $59.6 \%$ and $57.2 \%$ in $C x$. quinquefasciatus, respectively (Table 1). While $C x$.

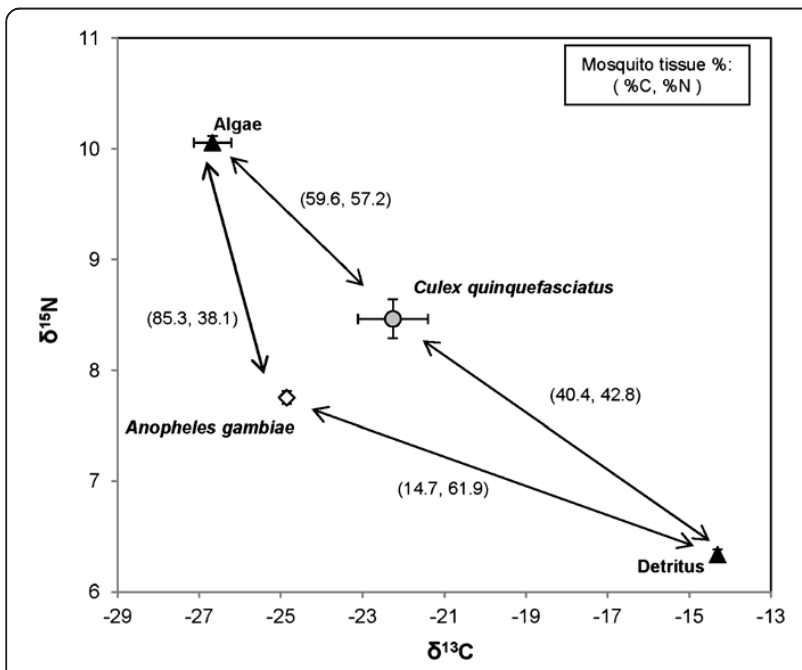

Figure 2 Microcosm experiment $\delta^{13} \mathrm{C}$ and $\delta^{15} \mathrm{~N}$ values for two larval species and two potential food resources. Arrows connect larvae to their potential food resources, and numbers in parentheses are the estimated percent carbon and percent nitrogen $(\% \mathrm{C}, \% \mathrm{~N})$ contribution.
Table 1 Two source mixing model estimates of dietary contributions to An. gambiae s.s. and Cx. quinquefasciatus larvae reared in microcosms

\begin{tabular}{lccccc}
\hline \multicolumn{4}{c}{ Mosquito tissue (est. \% contribution) \pm SE } \\
\hline & \multicolumn{2}{c}{ An. gambiae } & & Cx. quinquefasciatus \\
\cline { 2 - 3 } \cline { 6 - 7 } & Carbon & Nitrogen & & Carbon & Nitrogen \\
\hline Filamentous algae & $85.3 \pm 1.6$ & $38.1 \pm 1.8$ & & $59.6 \pm 0.6$ & $57.2 \pm 2.9$ \\
Detritus & $14.7 \pm 1.6$ & $61.9 \pm 1.8$ & & $40.4 \pm 0.6$ & $42.8 \pm 2.9$ \\
\hline
\end{tabular}

quinquefasciatus appeared to forage about equally between the algal and detrital, the isotopic signatures for An. gambiae was skewed (enriched in ${ }^{15} \mathrm{~N}$ and depleted in ${ }^{13} \mathrm{C}$ ), suggesting another, un-analyzed food source may have been contributing to the An. gambiae diet (Figure 2).

\section{Natural habitat sample collections}

In all four habitats Culex sp. were consistently depleted in $\delta^{13} \mathrm{C}$ relative to $A n$. gambiae. However, $\delta^{15} \mathrm{~N}$ did not clearly demonstrate partitioning of resources (Table 2). In all habitats with multiple anopheline species, the anophelines generally clustered together which may reflect the differences in morphology and foraging strategies between the two genera (Figure 3, Table 2). In 2011, we sampled cow dung from near the habitat edge as a third potential food source. A three source, dual isotope mixing model was not able to resolve the relationships of larvae to the potential food sources, suggesting the need for a more comprehensive sampling of potential food sources. Dragonfly nymphs were sampled from the same habitat. In the present study, a mixing model using isotopes of carbon and nitrogen suggested that An. funestus (53\%) and An. gambiae (47\%) make up the majority of contribution to dragonfly nymphs when compared to Culex sp. (0.1\%), (Figure 4).

\section{Discussion}

Laboratory experiments to determine the degree of trophic shift associated with larval metabolism demonstrated low levels of fractionation. Larvae of both An. gambiae and Cx. quinquefasciatus closely reflected their laboratory chow (fish food) diet. Further, when An. gambiae from the same

Table 2 ANOVA results of co-occurring anopheline and culicine $\delta^{13} \mathrm{C}$ and $\delta^{15} \mathrm{~N}$ signatures from natural habitats

\begin{tabular}{lccccc}
\hline & \multicolumn{2}{c}{$\boldsymbol{\delta}^{\mathbf{1 3}} \mathbf{C}$} & & \multicolumn{2}{c}{$\boldsymbol{\delta}^{\mathbf{1 5}} \mathbf{N}$} \\
\cline { 2 - 3 } \cline { 6 - 7 } Habitat & $\mathbf{F}_{\mathrm{df} \text {, error }}$ & $\boldsymbol{P}$ & & $\mathbf{F}_{\mathrm{df} \text {, error }}$ & $\boldsymbol{P}$ \\
\hline A) Goldmine 1 & $5.07_{1,7}$ & 0.0591 & & $10.91_{1,7}$ & $\mathbf{0 . 0 1 3 1}$ \\
B) Goldmine 2 & $48.82_{1,6}$ & $\mathbf{0 . 0 0 0 4}$ & & $0.23_{1,6}$ & 0.6460 \\
C) Goldmine 3 & $29.65_{1,6}$ & $\mathbf{0 . 0 0 1 6}$ & & $2.98_{1,6}$ & 0.1353 \\
D) Drainage ditch & $14.54_{1,4}$ & $\mathbf{0 . 0 1 8 9}$ & & $25.70_{1,4}$ & $\mathbf{0 . 0 0 7 1}$ \\
\hline
\end{tabular}

Habitat letters refer to panels in Figure 3. Significant $P$ values are in bold. 


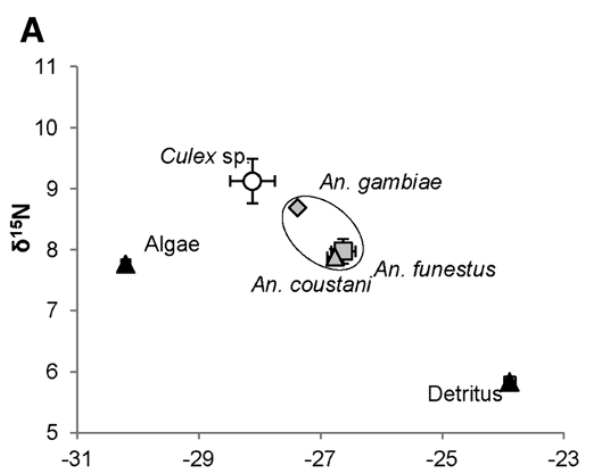

B

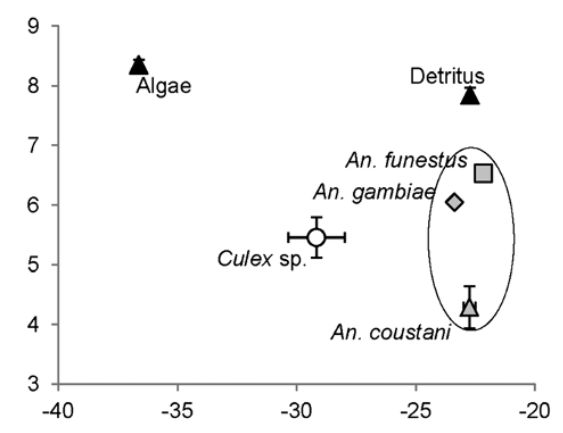

C

D

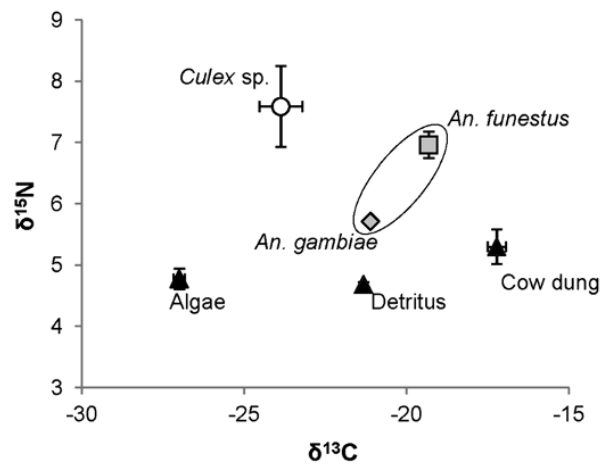

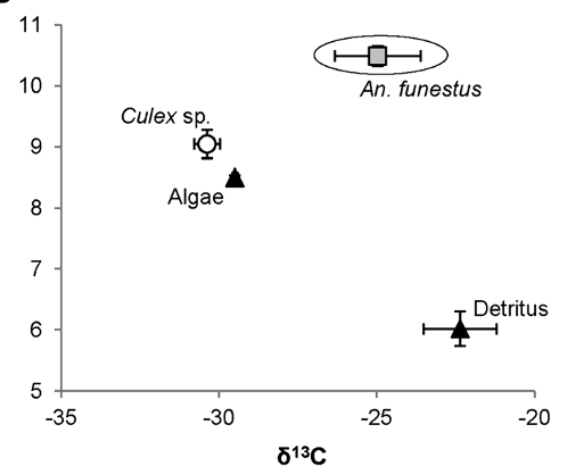

Figure $3 \delta^{13} \mathrm{C}$ and $\delta^{15} \mathrm{~N}$ values for larval species and food sources collected from natural habitats. Panels A-D show results from individual habitats that were sampled (Table 2). All larval species present in a habitat were sampled.

colony were reared on brewer's yeast, their isotopic composition was indicative of this alternative diet. In the subsequent field experiments, larval genera and species showed variable isotopic compositions consistent with laboratory results, which is indicative of resource partitioning. Kaufman also found that larval carbon and nitrogen isotopes reflected their food source [16]; however, higher

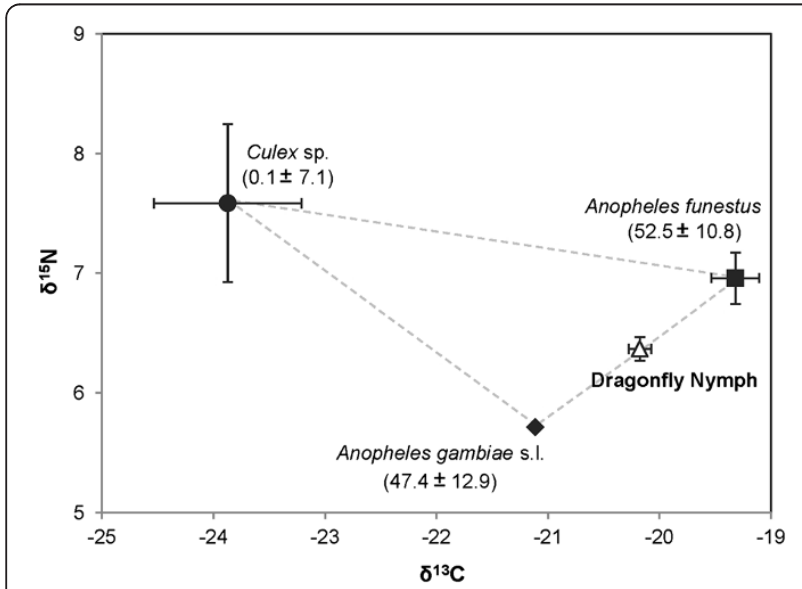

Figure 4 Three source, two isotope mixing model. Results estimate the dietary contribution (\% $\pm \mathrm{SE}$ ) of An. gambiae and CX. quinquefasciatus to dragonfly nymphs sampled from the same natural habitat. fractionation in larvae was observed when compared to the current study. Stable isotope values of $\delta^{15} \mathrm{~N}$ in Ae. albopictus and $C x$. restuans have suggested differences in assimilation or utilization efficiency of nitrogen [9]. In our laboratory studies the low level of trophic shift associated with An. gambiae and Cx. quinquefasciatus feeding allowed us to directly interpret differences in larval isotopic composition as evidence of resource partitioning in the subsequent microcosm and natural habitat experiments.

The partitioning of resources in the microcosms was striking, as evidenced by the relative differences between larval An. gambiae and Cx. quinquefasciatus $\delta^{13} \mathrm{C}$ and $\delta^{15} \mathrm{~N}$ signatures in microcosms. This is indicative of differential feeding on and/or assimilation of the resources available in microcosms. We hypothesized that partitioning would be less apparent in microcosms when compared to natural habitats. Bacteria, algae and protozoans make up a large proportion of the larval diet and can vary widely in different habitats depending on habitat duration, soil type and allochthonous inputs [26-28]. Due to limitations of food source diversity (i.e. little to no allochthonous plant material, debris, and a limited period for microbial growth), opportunities for larvae to forage on distinct resources are limited. Although the resources in microcosms are presumably less diverse than those found in natural habitats, we found more pronounced differences in microcosms. In 
addition to a highly diverse menu for larvae in natural habitats, difficulties in identifying resource partitioning in natural habitats using stable isotope analysis alone is also likely due to the long term mixing and nutrient turnover these habitats experience [14]. The resource portioning we found between these commonly co-occurring larvae may offer opportunities for species-specific targeted control. Shading habitats or using algaecides may have a negative impact on larvae associated with emergent algae and photosynthetic microbes, such as An. gambiae. For example, in western Kenya, shading agricultural drainage ditches with Napier grass, a regularly cultivated cow fodder, reduced larval populations of An. gambiae s.l. by $75-80 \%$ [29]. As observed, the shading did result in lower temperatures which can affect larval development [30]; however, it is likely that changes in the aquatic microbial community structure in response to shading may have played a role in the developmental success of larvae, and perhaps oviposition via volatile cues to the gravid female. Some of these interventions may not fully eliminate the target larval species, but in some cases, population reduction may lead to competitive exclusion of the target species.

Dragonfly nymphs had an isotopic composition indicative of a primarily anopheline diet. Although this result should be interpreted somewhat carefully since only three food sources were taken into account (Cx. quinquefasciatus, An. gambiae and An. funestus), studies suggest that culicine larvae may have a competitive advantage over anophelines when dragon fly nymphs are present in the habitat $[2,31]$. Our group reported a $70 \%$ reduction of $A n$. gambiae s.s. larvae exposed to dragonfly nymphs, and used PCR to confirm the presence of $A n$. gambiae DNA in the nymph gut content [21]. There may be other significant contributors to the nymph diet, but these resources would presumably occupy the same trophic level of the anophelines. Microcosm experiments with known predators and prey may help to evaluate the role of tropic structure in determining mosquito species success and habitat productivity.

In addition to more comprehensive food source sampling, stable isotopes may be useful in studying other aspects of vector ecology. Stable isotope ratios of oxygen and hydrogen are significantly affected by processes of evaporation and infiltration of ground water and rainwater, which will vary based on habitat size $[14,32]$. Thus, naturally occurring stable isotopes may potentially be used to address other problems in mosquito ecology, such as tracking adult dispersal from larval habitats. Variation in larval development conditions results in variable adult mosquito size and fitness [3,33], and determining the aquatic source of "successful" adult mosquitoes will provide useful insights for targeted vector control programs. Commercially available enriched compounds can also be used for such studies in the laboratory and the field. For example, Hamer et al. recently used ${ }^{15} \mathrm{~N}$-labeled potassium nitrate and ${ }^{13} \mathrm{C}$-labeled glucose to monitor dispersal of naturally breeding Culex pipiens mosquitoes [34].

As resource utilization and partitioning among larval mosquitoes can play a major role in determining mosquito species composition and survival in aquatic habitats, many studies have addressed the larval mosquito diet and identified differences in food preference largely based on gut content analyses [35,36]. The advantage of using a stable isotope method to examine resource partitioning is that carbon and nitrogen isotopes are assimilated into the larval body and contribute to the larval body mass whereas gut content analysis does not necessarily indicate assimilation.

\section{Conclusions}

Understanding the trophic relationships in larval mosquito habitats has broad implications for malaria vector management. Habitats with co-occurring culicine and anopheline larvae are common throughout western Kenya, and competitive interactions among co-occurring mosquito larval species play a role in regulating adult populations $[1,2]$. The current study demonstrated a high degree of resource partitioning between Cx. quinquefasciatus and An. gambiae larvae. This was most evident in the microcosm studies conducted in Kenya. Further, resource partitioning among culicines and anophelines in natural habitats was also demonstrated. This information can be translated into potential opportunities for targeted larval control efforts by limiting specific larval food resources or through bio-control, utilizing competitors at the same trophic level. Given that culicine and anopheline larvae have been shown to partition the resources available in their habitats, it may be possible to target key food resources as an indirect method of species-specific malaria control.

\section{Ethics statement}

No specific permits were required for the described field studies. These locations were not protected land, and the field studies did not involve endangered or protected species.

\section{Competing interests}

All authors declare they have no competing interest in this study.

\section{Authors' contributions}

TMG, GY and AKG conceived and designed experiments. TMG, YAA and EJK implemented and supervised the study. TMG did data analysis and interpretation. TMG wrote the manuscript. TMG, EJK and GY revised the manuscript. All authors approved the final version for submission.

\section{Acknowledgements}

We thank the members of the Yan Laboratory, Prof. Kathleen Treseder and Prof. Timothy Bradley at UC, Irvine for helpful discussion and expertise. This paper is published with the permission of the Director KEMRI.

\section{Author details}

${ }^{1}$ Ecology and Evolutionary Biology, University of California, 3501b Hewitt Hall, Irvine, CA 92697, USA. ²Division of Livestock and Human Diseases Vector 
Control, Mosquito Section, Tropical Pesticides Research Institute, Ngaramtoni, Off Nairobi Road, P.O. Box 3024, Arusha, Tanzania. ${ }^{3}$ Centre for Global Health Research, Kenya Medical Research Institute, P. O. Box 1578, Kisumu 40100, Kenya. ${ }^{4}$ Program in Public Health, University of California, Irvine, CA 92697, USA.

Received: 28 June 2013 Accepted: 2 December 2013

Published: 12 December 2013

\section{References}

1. Kirby $M$, Lindsay S: Effect of temperature and inter-specific competition on the development and survival of Anopheles gambiae sensu stricto and An. arabiensis larvae. Acta Trop 2009, 109(2):118-123.

2. Kweka EJ, Zhou G, Beilhe LB, Dixit A, Afrane Y, Gilbreath TM III, Munga S, Nyindo M, Githeko AK, Yan G: Effects of co-habitation between Anopheles gambiae ss and Culex quinquefasciatus aquatic stages on life history traits. Parasit Vectors 2012, 5:33.

3. Gimnig J, Ombok M, Otieno S, Kaufman M, Vulule J, Walker E: Density-dependent development of Anopheles gambiae (Diptera: Culicidae) larvae in artificial habitats. J Med Entomol 2002, 39(1):162-172.

4. Kaufman M, Walker E, Smith T, Merritt R, Klug M: Effects of larval mosquitoes (Aedes triseriatus) and stemflow on microbial community dynamics in container habitats. Appl Environ Microbiol 1999, 65(6):2661.

5. Walker E, Lawson D, Merritt R, Morgan W, Klug M: Nutrient dynamics, bacterial populations, and mosquito productivity in tree hole ecosystems and microcosms. Ecology 1991, 72(5):1529-1546.

6. Minakawa N, Sonye G, Yan G: Relationships between occurrence of Anopheles gambiae sl (Diptera: Culicidae) and size and stability of larval habitats. J Med Entomol 2005, 42(3):295-300.

7. Bayoh M, Lindsay S: Temperature related duration of aquatic stages of the Afrotropical malaria vector mosquito Anopheles gambiae in the laboratory. Med Vet Entomol 2004, 18(2):174-179.

8. Bayoh M, Lindsay S: Effect of temperature on the development of the aquatic stages of Anopheles gambiae sensu stricto (Diptera: Culicidae). Bull Entomol Res 2003, 93(05):375-381.

9. Winters AE, Yee DA: Variation in performance of two co-occurring mosquito species across diverse resource environments: insights from nutrient and stable isotope analyses. Ecol Entomol 2012, 37(1):56-64.

10. Gimnig J, Ombok M, Kamau L, Hawley W: Characteristics of larval anopheline (Diptera: Culicidae) habitats in Western Kenya. J Med Entomol 2001, 38(2):282-288.

11. Minakawa N, Mutero C, Githure J, Beier J, Yan G: Spatial distribution and habitat characterization of anopheline mosquito larvae in Western Kenya. Am J Trop Med Hyg 1999, 61(6):1010.

12. Service M: Mortalities of the immature stages of species $B$ of the Anopheles gambiae complex in Kenya: comparison between rice fields and temporary ponds, identification of predators and effects of insecticidal spraying. J Med Entomol 1977, 13:535-545.

13. Sunahara T, Ishizaka K, Mogi M: Habitat size: a factor determining the opportunity for encounters between mosquito larvae and aquatic predators. J Vector Ecol 2002, 27:8-20.

14. Hood Nowotny R, Knols B: Stable isotope methods in biological and ecological studies of arthropods. Entomol Exp Appl 2007, 124(1):3-16.

15. Hood-Nowotny R, Mayr L, Knols BGJ: Use of carbon-13 as a population marker for Anopheles arabiensis in a sterile insect technique (SIT) context. Malar J 2006, 5(1):6.

16. Kaufman MG, Pelz-Stelinski KS, Yee DA, Juliano SA, Ostrom PH, Walker ED: Stable isotope analysis reveals detrital resource base sources of the tree hole mosquito, Aedes triseriatus. Ecol Entomol 2010, 35(5):586-593.

17. Edward D, Newton J, Gilburn A: Investigating dietary preferences in two competing dipterans, Coelopa frigida and Coelopa pilipes, using stable isotope ratios of carbon and nitrogen. Entomol Exp App/ 2008, 127(3):169-175.

18. McNeely C, Finlay J, Power M: Grazer traits, competition, and carbon sources to a headwater-stream food web. Ecology 2007, 88(2):391-401.

19. Brito E, Moulton T, De Souza M, Bunn S: Stable isotope analysis indicates microalgae as the predominant food source of fauna in a coastal forest stream, south east Brazil. Austral Ecol 2006, 31(5):623-633.

20. Post D: Using stable isotopes to estimate trophic position: models, methods, and assumptions. Ecology 2002, 83(3):703-718.
21. Kweka E, Zhou G, Gilbreath T, Afrane Y, Nyindo M, Githeko A, Yan G: Predation efficiency of Anopheles gambiae larvae by aquatic predators in western Kenya highlands. Parasit Vectors 2011, 4(1):128.

22. McCutchan JH, Lewis WM, Kendall C, McGrath CC: Variation in trophic shift for stable isotope ratios of carbon, nitrogen, and sulfur. Oikos 2003, 102(2):378-390

23. Wang Y, Gilbreath TM, Kukutla P, Yan G, Xu J: Dynamic Gut Microbiome across Life History of the Malaria Mosquito Anopheles gambiae in Kenya. PLoS One 2011, 6(9):e24767.

24. Wang W, Pataki DE: Drivers of spatial variability in urban plant and soil isotopic composition in the Los Angeles basin. Plant Soil 2011, 350:323-338.

25. Phillips DL, Gregg JW: Uncertainty in source partitioning using stable isotopes. Oecologia 2001, 127(2):171-179.

26. Merritt $\mathrm{R}$, Craig D, Wotton R, Walker E: Feeding behavior of aquatic insects: case studies on black fly and mosquito larvae. Invertebr Biol 1996, 115(3):206-217.

27. Merritt RW, Dadd RH, Walker ED: Feeding behavior, natural food, and nutritional relationships of larval mosquitoes. Annu Rev Entomol 1992, 37(1):349-374.

28. Kaufman M, Wanja E, Maknojia S, Bayoh M, Vulule J, Walker E: Importance of algal biomass to growth and development of Anopheles gambiae larvae. J Med Entomol 2006, 43(4):669-676.

29. Wamae P, Githeko A, Menya D, Takken W: Shading by Napier Grass Reduces Malaria Vector Larvae in Natural Habitats in Western Kenya Highlands. Eco Health 2010, 7:485-497.

30. Afrane YA, Githeko AK, Yan G: The ecology of Anopheles mosquitoes under climate change: case studies from the effects of deforestation in East African highlands. Ann N Y Acad Sci 2012, 1249:204-210.

31. Kumar R, Ramakrishna Rao T: Predation on mosquito larvae by Mesocyclops thermocyclopoides (Copepoda: Cyclopoida) in the presence of alternate prey. Int Rev Hydrobiol 2003, 88(6):570-581.

32. Peterson B, Fry B: Stable isotopes in ecosystem studies. Annu Rev Ecol Syst 1987, 18:293-320.

33. Afrane Y, Zhou G, Lawson B, Githeko A, Yan G: Effects of microclimatic changes caused by deforestation on the survivorship and reproductive fitness of Anopheles gambiae in western Kenya highlands. Am J Trop Med Hyg 2006, 74(5):772.

34. Hamer GL, Donovan DJ, Hood-Nowotny R, Kaufman MG, Goldberg TL, Walker ED: Evaluation of a stable isotope method to mark naturally-breeding larval mosquitoes for adult dispersal studies. J Med Entomol 2012, 49(1):61-70.

35. Garros C, Ngugi N, Githeko A, Tuno N, Yan G: Gut content identification of larvae of the Anopheles gambiae complex in western Kenya using a barcoding approach. Mol Ecol Resour 2008, 8(3):512-518.

36. Walker ED, Olds EJ, Merritt RW: Gut content analysis of mosquito larvae (Diptera: Culicidae) using DAPI stain and epifluorescence microscopy. J Med Entomol 1988, 25(6):551-554.

doi:10.1186/1756-3305-6-353

Cite this article as: Gilbreath et al.: Evaluating larval mosquito resource partitioning in western Kenya using stable isotopes of carbon and nitrogen. Parasites \& Vectors 2013 6:353.

\section{Submit your next manuscript to BioMed Central and take full advantage of:}

- Convenient online submission

- Thorough peer review

- No space constraints or color figure charges

- Immediate publication on acceptance

- Inclusion in PubMed, CAS, Scopus and Google Scholar

- Research which is freely available for redistribution 